\title{
A CONSTRUÇÃO DE NARRATIVAS EUROCÊNTRICAS NA SOCIEDADE ZAMBEZIANA DO SÉCULO XIX
}

\section{THE CONSTRUCTION OF EUROCENTRIC NARRATIVES IN NINETEENTH-CENTURY ZAMBEZIAN SOCIETY}

\author{
Iamara de Almeida Nepomuceno ${ }^{1}$
}

Recebido: 15 fev. 2019

Aceite: 05 mai. 2019

DOI https://doi.org/10.29327/2.1373.1-9

RESUMO: Abordaremos neste artigo o espaço dos prazos zambezianos como território de contato entre culturas afro-portuguesa e passível de análise de evidências do poder feminino e de tal exercício de poder de Luísa do Goengue como “dona na Zambézia”, na segunda metade do século XIX. Possuía o prazo do Goengue localizado no vale do Zambeze, situado em Moçambique atual. As discussões da historiografia colonial sobre os territórios dos prazos ficaram, durante muito tempo, restritas ao debate político e ideológico direcionado para a estrutura dos prazos com ênfase na sua origem, processo de transformação, estrutura social política e econômica subjacente a isto estava uma perspectiva eurocêntrica da construção do conhecimento histórico de Moçambique.

PALAVRAS-CHAVE: Mulheres africanas; Moçambique; Zambeze; África.

\begin{abstract}
We will discuss in this article the space of Zambezian terms as a contact territory between Afro-Portuguese cultures and capable of analyzing the evidence of feminine power and of this exercise of power of Luísa do Goengue as "dona na Zambézia", in the second half of the century XIX. It had the Goengue term located in the Zambezi Valley, situated in present-day Mozambique. The discussions of colonial historiography on the territories of the periods were, for a long time, restricted to the political and ideological debate directed to the structure of the periods with emphasis on its origin, transformation process, political and economic social structure underlying this was a Eurocentric perspective the construction of historical knowledge of Mozambique.
\end{abstract}

KEYWORDS: African women; Mozambique; Zambezi; Africa.

\footnotetext{
1 Mestranda em História Social pela Universidade de São Paulo (USP). Técnica em Educação no Instituto Federal de São Paulo (IFSP). E-mail: iamara.nepomuceno@ifsp.edu.br ORCID iD https://orcid.org/0000-0001-6811-7991
} 


\section{INTRODUÇÃO: ANÁLISE DAS FONTES E A CONSTRUÇÃO DE NARRATIVAS}

As discussões da historiografia colonial sobre os territórios dos prazos ficaram, durante muito tempo, pautadas no debate político e ideológico direcionado para sua estrutura com ênfase na origem, processo de transformação, estrutura social, política e econômica e por fim, subjacente a isso, a perspectiva eurocêntrica da construção do conhecimento histórico sobre Moçambique. Este debate estava posto na década de 1890, quando houve a formação de uma comissão exclusiva para pensar os desafios sofridos pelos lusitanos nos territórios sob sua influência. Com vistas a transformar aquele território moçambicano em uma colônia essencialmente produtiva do ponto de vista capitalista organizaram-se os estudos coloniais que delinearam por décadas a história de Moçambique, principalmente aquela que diz respeito aos territórios de contato, os prazos².

Tendo como relator oficial Oliveira Martins (1920), o objetivo geral desta comissão era estudar os territórios dos prazos, buscando argumentos que viabilizassem sua extinção; e, mais especificamente, objetivaram vislumbrar novas possibilidades de exploração econômica dos povos e das matérias-primas existentes na região do vale do Zambeze além das outras áreas do contato entre os tonga e os portugueses. Isto ocorreu porque os enfrentamentos políticos e militares impostos por parte das chefias africanas e dos senhores dos prazos vinham impossibilitando o domínio efetivo do território e o desenvolvimento econômico nos moldes de uma colonização pretendida por Portugal no final do século XIX.

O desenvolvimento dos estudos sobre os prazos oscilou entre o debate anteriormente mencionado e as discussões que se focalizaram na sociedade zambeziana como atrasada e com urgente necessidade de intervenção militar. Tal ação já estava em andamento em 1880 e foi sendo ampliada no contexto da Partilha da África, tendo sido intensificadas com as "campanhas de pacificação", como foram denominadas as guerras militares travadas contra as diferentes chefias africanas, no período final do século XIX.

\footnotetext{
2 Os territórios dos prazos surgiram a partir do contato, principalmente, entre os povos africanos e portugueses (afroportugueses), uma sociedade organizada no percurso do rio Zambeze e que Portugal tentou controlar, agindo como se possuísse efetivamente há muito tempo tais territórios. No entanto, durante longo tempo, as relações políticas sociais e culturais na região foram estabelecidas seguindo o ritmo e ditames já estabelecidos pelas sociedades africanas.
} 
Nesse contexto, foram ampliadas as alterações nos discursos em torno das famílias que se colocaram contrárias às mudanças no sistema de relações comerciais e políticas. Discursos contrários às famílias prazeiras emergiram e passaram do tom majoritariamente colaborativo para a descrição pejorativa, preconceituosa e acusatória de traição sobre elas.

A família Cruz, objeto de nosso estudo, passou por um processo análogo a isso. Enquanto seus membros colaboravam e comercializavam diretamente com os portugueses a família era descrita como importante aliada e muitos de seus membros tidos como pessoas prestativas aos interesses da coroa portuguesa. No entanto, quando passaram a questionar as ingerências da coroa lusa e até mesmo a tomar para si os carregamentos das caravanas, os prazeiros foram tachados como pessoas bárbaras e cruéis sendo constantemente animalizados nos textos dos administradores e militares portugueses.

Como um ícone desse processo de demonização na historiografia, apontamos a personagem histórica Luísa Micaela Rita da Cruz que teve suas ações apresentadas de maneira ambígua. Ora tratada como heroína, dócil e prestativa ora descrita como traidora, cruel e sanguinária. Em sentido contrário a esta representação, buscaremos ir além da aparente ambiguidade para aprofundar aspectos da atuação de Luísa que esclareçam seus papéis político e social, em seu cotidiano, sem que isso seja erigido a categorias mitificadas ou lendárias.

Para isto, torna-se importante pensar os discursos produzidos sobre ela e sua família, os Cruz, como fonte histórica, pois tanto as fontes quanto os textos historiográficos, trazem não só a reflexão sobre de seus autores, mas também mostram como eles pensaram a sociedade dos prazos à época. Igualmente, no que diz respeito à narrativa construída sobre Luísa, este conteúdo também possui um teor importante a ser problematizado.

Desta forma, a partir da análise discursiva proposta por Mikhail Bakhtin (2003) podemos perceber a intencionalidade do autor na produção da narrativa, bem como os sujeitos referidos nos discursos, uma vez que, os gêneros dos discursos são, para ele, vertentes que a língua elabora como "tipos de enunciados relativamente estáveis" e que, portanto, se revelam heterogêneos, multiformes e se organizam em campos complexos e, a medida que se desenvolvem, podem variar de acordo com o tema. 
A partir da análise discursiva poderemos discutir a participação de Luísa nos processos históricos de guerra, reorientando os debates para pensar sobre esta senhora como comerciante e mulher com poder político. Neste sentido, partimos da hipótese de que suas ações podiam estar mais relacionadas com as questões econômicas, familiares da sua linhagem e as consequências que a guerra acarretou a ela do que com o fato de que ela era uma mulher com dupla personalidade como aparece na historiografia colonial e pós-colonial.

Como possibilidade de análise discursiva construídos em torno desta personagem, empregaremos o princípio dialógico da linguagem, teoria proposta por Mikhail Bakhtin (2003), a qual considera que as palavras expressam os valores contraditórios de seu locutor, cuja interpretação da realidade observada e vivida é feita pelo interlocutor, carregada de signos de suas experiências vividas e valores implícitos a sua realidade de origem. Considerando que os gêneros discursivos, compõe um elo entre a história da sociedade e a história da linguagem, conforme proposto por Bakhtin, consolidam uma forma específica de comunicação e, por conseguinte, da construção de memórias e de conhecimento sobre a África.

Os enunciados e seus tipos, isto é, os gêneros discursivos, são correias de transmissão entre a história da sociedade e a história da linguagem. Nenhum fenômeno novo (fonético, léxico, gramatical) pode integrar o sistema da língua sem ter percorrido um complexo e longo caminho de experimentação e elaboração de gêneros e estilos (BAKHTIN, 2003, p. 268).

É preciso que se diga que este tipo de metodologia investigativa é possível ser feita nos dias de hoje graças à ampliação do que se definia como fonte histórica, daí a possibilidade de pensar os processos narrativos construídos pelos viajantes franceses e administradores portugueses sobre os prazos da Zambézia, eles mesmos como fonte histórica. Em nosso entendimento,

(...) são fontes históricas tanto os já tradicionais documentos textuais (crônicas, memórias, registros cartoriais, processos criminais, cartas legislativas, obras de literatura, correspondências públicas e privadas e tantos mais) como também quaisquer outros que possam nos fornecer um testemunho ou um discurso proveniente do passado humano, da realidade um dia vivida e que se apresenta como relevante para o Presente do historiador (BARROS, 2012, p. 130). 
Neste sentido, reafirmamos a importância de pensar as narrativas por eles registradas como uma possibilidade documental, tendo em vista que a fonte histórica é "um discurso proveniente do passado humano" (BARROS, 2012, p. 130). Atribuímos este movimento interpretativo, na esteira de outros historiadores, como José d'Assunção Barros (2012), à expansão dos limites da historiografia no século XX cuja finalidade se direcionava para buscar um tratamento mais aprofundado das fontes em detrimento de uma leitura permeada de superficialidade.

Desta forma, existe a clareza de que escolha dos meios linguísticos e dos gêneros de discurso é determinada, antes de tudo, pelas tarefas e pela ideia do sujeito do discurso, ou autor, centradas no objeto e no sentido que se quer dar a ele. E o primeiro momento do enunciado que determina as suas peculiaridades estilístico-composicionais (BAKHTIN, 2003, p. 289).

Por fim, a partir dessa reflexão de Bakhtin, continuamos nossa discussão trazendo os aspectos históricos que organizam a produção da narrativa sobre a família Cruz e Luísa do Goengue. Esperamos com isso estabelecer uma "avaliação da posição ideológica" ocupada pelos estrangeiros na Zambézia no XIX, pois isto nos "permite introduzir uma nova postura historiográfica, que é a de tratar a fonte-autoral não como testemunho ou fonte de informações, mas como discurso a ser analisado" (BARROS, 2012, p. 136).

\section{OS PRAZOS E A FAMÍLIA CRUZ NA HISTORIOGRAFIA}

No século XX, em pleno período da colonização efetiva, Alexandre Lobato (1962) escreveu a história dos prazos sob um viés de análise jurídico por meio do qual definiu que a posse da terra dos prazos era transmitida pelas mulheres por três gerações, conectando assim as relações entre prazeiros e a coroa portuguesa. Seu estudo apresentou, sem maiores preocupações, as relações mantidas dentro do prazo ou mesmo as mantidas entre os prazeiros e os reinos africanos e as chefias locais. Neste sentido, abordou a presença das mulheres na região dos prazos para demonstrar a ligação entre as chamadas elites locais e Portugal, neste caso, a atuação feminina figura como elemento meramente ilustrativo. 


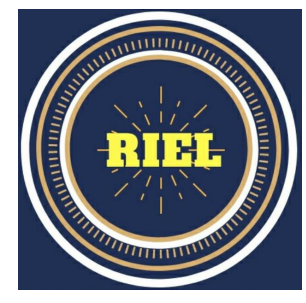

Já nos estudos de José Capela (1995) surgiu a preocupação com a História das mulheres, em recuperar as personalidades históricas por meio da reconstituição do pertencimento das famílias e daquilo que ele afirma ser a elite colonial. Pautou-se na ideia de que essas mulheres, chamadas de donas por seus contemporâneos, estavam inseridas como súditas do rei e que, de maneira geral, participavam do processo de colonização tal qual ordenado pela coroa, cumprindo as suas ordens, salvo algumas exceções.

Desta forma, esse historiador resgatou os nomes portugueses e os apelidos locais atribuídos a essas mulheres e os prazos dos quais obtiveram a posse, além de alguns aspectos ligados à representação que as fontes deixadas por oficiais portugueses, militares ou administrativos registraram sobre elas. Trata diretamente de Luísa do Goengue, informando que as fontes utilizadas para reconstituir sua história são ambíguas, não permitindo assim um juízo acerca de seu comportamento. $\mathrm{O}$ autor apresentou em sua obra, uma sequência de relatos sobre os atributos de beleza física, representações de viajantes em torno de suas atitudes, cujas ações foram definidas como despóticas ou benevolentes no tratamento despendido para com os portugueses ou seus subordinados.

No século XIX, diversos viajantes observaram e registraram as sociedades locais. E foi por meio destes documentos que entrevemos as agências históricas africanas mais propícias para entender como ocorreu a participação de Luísa do Goengue no contexto da guerra entre os portugueses e as gerações de senhores de Massangano.

Optamos por analisar tais relatos a luz do conceito de "Africanização" proposto por Allen Isaacman (1972), para quem as sociedades afro-portuguesas zambezianas foram sendo moldadas a partir da lógica cultural e política das sociedades africanas, além disto, utilizamos depois deste primeiro conceito, dois outros, a saber, o segundo conceito refere-se ao tema proposto pelo estudioso Alfredo Margarido que buscou ressaltar e localizar as formas de hegemonia africana. A ideia de Hegemonia, neste caso, refere-se ao domínio ou controle africanos nos parâmetro e valores das relações de poder, no âmbito cultural, social ou político (1998). E o terceiro conceito, de gênero, situado no contexto mais amplo da história das mulheres será apresentado no texto mais adiante. 
Utilizamos as fontes de viajantes para discussão sobre os prazos na Zambézia e sobre a dona Luísa. Assim selecionamos as seguintes obras dos viajantes franceses para análise: Voyage au Zambèse de Paul Guyot (1892), A l'est et à l'ouest dans l'Océan Indien de Charles Courret (1884) e Exploration au Zambèse: situation géographique et aspect du pays, flore, faune, habitants de Rodolphe Gaffard (1882). Elas foram produzidas como resultado da expedição luso-francesa comandada pelo explorador e oficial militar português Joaquim Carlos Paiva de Andrada durante sua viagem ao vale do Zambeze, aos chamados prazos da Coroa de Quelimane à Tete e até o Zumbo, entre 1881 e 1882.

Financiados pelo capital privado de Andrada e de seus associados franceses, essa expedição técnica de prospecção do solo foi enviada de Paris para estudar diversos depósitos de minerais, principalmente, das reservas de carvão no vale do Zambeze. Ela foi composta por 12 especialistas e dividida em diferentes expedições que faziam parte da exigência imposta pelo governo português e francês. Tal exigência era a contrapartida a uma concessão portuguesa de exploração privada no vale do Zambeze feita em 1878 a Andrada e associados franceses, quando fundaram a companhia Société des Fondateurs de la Compagnie Générale du Zambeze.

Assim apresentaremos alguns apontamentos iniciais de resultados da confrontação de olhares sobre o mesmo contexto histórico fato que nos permitiu adensar a análise das fontes e consequentemente, o conteúdo que ela forneceu para o entendimento do período estudado. E ainda, utilizamos referenciais teórico-metodológicos para analisar a trajetória da personagem histórica Luísa do Goengue, a partir de questões propostas pelas novas abordagens da História Social para a história das mulheres e de gênero.

A historiadora que ampliou as novas abordagens no Brasil foi Maria Odila L. S. Dias que em seu texto Novas subjetividades na pesquisa histórica feminista: uma hermenêutica das diferenças (1994) expõe perspectivas de análises que se mostram imprescindíveis para a observação e o tratamento das fontes, a saber, a mitificação da figura feminina, a construção de padrões de comportamento relacionados à constituição de poder, o lugar do feminino, os papéis sociais das mulheres, bem como seus desdobramentos no domínio da informalidade, do cotidiano, dos contextos de sua produção, assim como as relações hierárquicas raciais. 


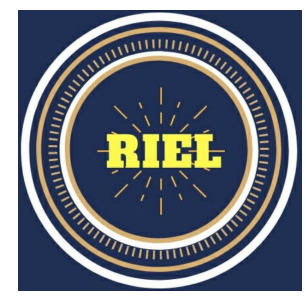

Estas perspectivas se configuram, como pontos centrais para a operação historiográfica e a ação de dar historicidade aos conceitos universalizantes e generalistas, servindo consequentemente para desmistificar tais concepções.

Além destas noções, vimos também que as expressões das subjetividades femininas no cotidiano, os mecanismos de observação destes aspectos nas fontes, seja por meio das cartas ou de desdobramentos de processos judiciais, foram caminhos que também coadunaram para o entendimento acerca do cotidiano e das experiências vividas por mulheres.

Estas dimensões de análise também fazem parte do universo que procuramos entender no contexto dos prazos uma vez que Luísa foi presa e acusada de traição. Isso impactou a sociedade zambeziana de tal forma que ocorreram manifestações para sua soltura imediata, com repercussão inclusive, por meio de jornais de circulação no litoral em Quelimane.

\section{POSSIBILIDAdES E ABORdAgENS HISTÓRICAS PARA PENSAR A TRAJETÓRIA DE LUÍSA MICHAELA RITA DA CRUZ}

Somando-se as já referidas concepções historiográficas destacamos as abordagens teóricometodológicas das obras das historiadoras Maria Cristina C. Wissenbach em especial seu texto Teodora Dias da Cunha: construindo um lugar para si no mundo da escrita e da escravidão (2012); e ainda os capítulos da tese de Juliana P. Magalhães intitulada de Trajetórias e resistências de mulheres sob o colonialismo português (2016).

Nos textos dessas historiadoras, a experiência social experimentada pelas mulheres seja por imposição de sua condição de subalternidade enquanto pertencente ao grupo social de pessoas que foram escravizadas no primeiro caso, seja pela resistência à opressão colonial, no segundo caso, nos confere um olhar em que a sensibilidade histórica apresentada que humaniza as personagens históricas são trazidas ao centro de tais estudos. Esse tratamento é imposto devido à invisibilidade histórica que assolou durante muito tempo aqueles sujeitos históricos encontrados nas camadas menos abastadas da sociedade. Ou ainda, pela simples razão de pertencer ao gênero feminino, dentro determinadas sociedades. 
Assim, as reconstruções históricas acerca da vida e do cotidiano ao qual estão imersas as mulheres, como sujeitos históricos e objetos de estudo feitos pelas autoras acima referidas, ampliam e dão condição a uma dimensão mais aprofundada dos contextos históricos nos quais se situam tais objetos de análise porque apresentam a reconstituição de agências de figuras sociais que viveram no período antes da efetiva colonização europeia.

No século XIX, as mulheres donas de prazos já tinham consolidado proeminência nas sociedades do vale do Zambeze. Constituíram seu poder por meio da participação no comércio de longa distância e no comércio de pessoas que foram escravizadas, por produtos agrícolas extraídos da natureza ou cultivados em pequena escala, além do garimpo do ouro entre outras formas de atividades econômicas, políticas e sociais. Entre estas, Luísa Michaela Rita da Cruz, também conhecida como Luísa do Goengue, se destacou na historiografia pela acusação de participação das rebeliões promovidas por seu irmão, o Bonga, cujo nome é António Vicente da Cruz, na Guerra de Massangano.

Neste sentido, estudamos sobre dona Luísa e os prazos da Zambézia por meio do aporte historiográfico referido acima e percebemos algumas características de sua participação nas guerras contra os portugueses, principalmente no final da década de 1880. No processo de construção das narrativas históricas em torno dessa consolidação da presença portuguesa no vale do Zambeze e dos atores que deles teriam participado de forma direta ou indireta, principalmente daquelas memórias evocadas no processo da guerra entre os chefes africanos incluindo os chefes dos Estados militarizados. Foram mobilizadas notícias que teriam causado certa discrepância nos registros em torno de dona Luísa no Goengue.

Igualmente averiguamos quais eram as fontes que emitiram discursos desqualificadores sobre dona Luísa e então constatamos que esses discursos foram sendo emitidos de maneiras distintas desde a primeira guerra entre a sua família e os portugueses. Se num primeiro momento, na década de 1860, os oficiais retratavam uma senhora dona de prazo amigável e acolhedora, duas décadas depois, suas ações e imagens foram sendo associadas ao despotismo e crueldade. Daí as contradições das narrativas que se tornaram evidenciadas por José Capela. 
Entrementes, em decorrência da mobilização desses diferentes discursos representativos, configuraram-se mitos sobre Luísa. Dentre eles destacamos os dois principais: Luísa era espiã, agindo ora em favor dos portugueses a fim de adquirir informações, suprimentos ou qualquer outro material, ora em favor do Bonga, pois este já estava com a posse daquelas informações e recursos materiais. Portanto, assim ela conseguiria auxiliar o irmão rumo à derrota dos portugueses frente ao Bonga e seus achikundas, ou escravos guerreiros; o outro mito recaiu sobre representação de crueldade que pesaria sobre ela, i.e. o suposto assassinato de seus maridos, todos eles portugueses.

Luísa foi dona do prazo do Goengue, localizado nas proximidades de Massangano, na região da Lupata. Este local serviu originalmente como base fortificada dos ataques dos portugueses contra o Bonga e seu prazo entre as décadas de 1860 a 1880.

$\mathrm{Na}$ documentação, foi apresentada como uma personagem histórica que não passou despercebida por seus contemporâneos ou mesmo pela historiografia. Foi caracterizada como uma mulher adulta e de pele negra, de descendência africana pertencente à família de linhagem real do Monomotapa e também de origem afro-portuguesa (CAPELA, 1995, p. 90).

Em seu cotidiano social e político contido em diferentes episódios que as fontes nos permitem analisar buscando entender qual o espaço sociopolítico por ela ocupado, destacamos sua ligação com o reino do Monomotapa, uma vez que como membro desta realeza e aliada aos portugueses por meio de casamento adquiriu um status quo diferenciado na sociedade a qual pertencia.

Ainda não dispomos de acesso a fontes que remetem a fase inicial da vida desta personagem. Sabemos que era bisneta de Nicolau Pascoal da Cruz o primeiro membro da família Cruz a se fixar na Zambézia. Segundo diferentes estudos, Neta de Cassere, membro da realeza do Monomotapa cujo casamento com Antônio José da Cruz, o Bereco, gerou como descendente Joaquim José da Cruz, Inhaúde ou Nhaúde pai de Luísa; (GARLAKE; NEWITT, 1967, p. 136). Cassere era irmã do rei do Monomotapa e não encontramos ainda evidências que revele seu nome completo. O matrimônio com Antônio José da Cruz é fruto de aliança política entre o Monomotapa e portugueses, sendo uma prática comum entre os tonga, povo ao qual ela pertencia (GARLAKE; NEWITT, 1967, p. 144). 
O nome de batismo recebido por nossa personagem histórica foi Luísa Micaela Rita da Cruz cuja alcunha seus contemporâneos portugueses e viajantes converteram em apelido: Luísa do Goengue. Acerca de seu nome podemos afirmar que tal registro marca a fusão cultural propiciada a partir da presença indo-portuguesa fruto de herança paterna. Sua origem é multiétnica, refletindo assim o próprio território geográfico e sociocultural da Zambézia desta época.

Residiu a maior parte de sua vida no prazo do Goengue, lugar ao qual obteve acesso como dona por causa de herança após a morte de seu pai. Mas, do ponto de vista português, isto ocorreu quando do casamento com um marido português que propiciou a doação enfitêutica. Sobre esta doação, percebemos que há uma demanda por analisar mais detalhadamente a origem do acesso à terra por Luísa. Por enquanto nós consideramos da proposição da historiografia colonial que as terras foram doadas para ela.

A relação entre dona Luísa e os portugueses foi marcada pela ambiguidade uma vez que, estabelecido o conflito, prevalece, pelo que as fontes deixam entrever, os laços familiares. Ela foi casada com pelo menos quatro oficiais portugueses, numa demonstração de que as alianças entre os membros de sua família e portugueses eram importantes para o processo de construção das relações entre as duas partes. No entanto, durante os episódios da guerra apresentou comportamentos que deixaram os oficiais portugueses em dúvida quanto a sua obediência e lealdade à Coroa.

À época da primeira expedição portuguesa contra o Bonga, em 1867, dona Luísa estava casada com o sargento Belchior. Neste contexto, ao chegar à aringa, uma povoação fortificada, do Bonga, e deparando-se com a sua ausência, essa expedição partiu para ocupá-la. De posse da informação de um soldado de que seriam enviados reforços da gente do Belchior, outros soldados da expedição animaram-se e comemoraram. No entanto, ocorreu uma emboscada à expedição. Ali foram mortos quase todos os 800 auxiliares, 46 das 67 praças, 6 oficiais, e outros reféns e o próprio governador do Distrito de Tete Miguel Augusto Gouveia que foi o responsável por organizar e comandar a expedição.

Neste episódio, destacamos como evidência que comprova o auxílio de Luísa ao irmão, o detalhe dos soldados que se diziam reforços enviados. O ponto inicial da trama envolvendo e acusando a dona Luísa é o fato de esses terem se apresentado como gente de Belchior. Depois desta 
batalha, ela ficou a cargo de pacificar as relações entre o seu irmão Bonga e o governador interino de Tete. Mas, as sequências dos fatos se deram em outro sentido percorrendo o caminho de uma série de episódios de guerra com reveses portugueses.

O prazo do Goengue localizava-se na margem direita do Zambeze, "inacessível às cheias do rio". Foi apontado por um dos principais oficiais como local estratégico para ataque à aringa, isto é, à fortificação do Bonga, e como um excelente "ponto para depósito" de alimento e armas, devido aos fatores já mencionados (FERREIRA, 1870, pp. 5-6). Neste sentido, esse prazo recebeu importante atenção dos militares portugueses.

Nas demais expedições, o prazo do Goengue serviu como base de concentração de alimentos e armas, principalmente em 1869, sendo esta expedição a maior derrota de todas sofrida pela coroa lusitana. $\mathrm{O}$ final dela foi completamente desfavorável à expedição armada portuguesa, sobejando inúmeros mortos e outros tantos reféns nas mãos dos guerreiros africanos. Luísa foi acusada pelo oficial Ferreira, em seu texto relançado 20 anos depois deste registro sobre a mobilização contra Massangano, de desviar os alimentos e armas. Neste sentido, houve uma grande disputa nos jornais pela manutenção memória da guerra.

Teve seu segundo casamento descrito nas fontes como unilateralmente interessante ou vantajoso para Machado, posto como sedutor infalível que visava lucrar à custa da recém-viúva. Machado era um representante militar português com patente designada. Logo, fazia parte de um reduzido escalão militar português no Zambeze.

A narrativa em torno dos primeiros contatos e casamento entre Luísa e Machado apresenta-o como oportunista. Pois, ele sabendo do recente revés sofrido pelos portugueses, fato que culminou na morte de Belchior, e da viúvas de Luísa, movimentou-se rapidamente no sentido de seduzir a viúva. Disse que houve rapidamente a negociação para selar os laços matrimoniais cujo ritual foi realizado tal qual um casamento tradicional dos tonga. Salientamos, no entanto, que o casamento aqui mencionado foi na verdade o estabelecimento de uma aliança que provavelmente teve interesses mútuos mobilizados para ter sido concretizado.

Mas, a controvérsia da narrativa de sedutor rapidamente se desfez e passou a ser proliferada a ideia de que Luísa assassinou Machado porque ele a abandonou e fugiu para Quelimane. Nesse 
episódio narrado por Courret, a volta do militar é realizada mediante escolta de achikunda, cuja ação se deu por ordens da esposa, a dona Luísa. Pouco tempo depois, Machado morreu aparentemente vítima de envenenamento.

Castilho, Governador Geral da região dos prazos na época, reforçou a imagem dela como alguém capaz de atrocidades, como não dotada de sentimentos humanos, uma "fera" que ataca e mata sem menor constrangimento. Ao longo da guerra de 1888, dona Luísa foi presa pela segunda vez sob as ordens de Castilho, acusada de envolvimento com as rebeldias dos irmãos Chiuta e Fikuza sucessores do Bonga, cuja morte se deu em 1877.

No ano de 1889, dona Luísa morreu na prisão de Quelimane. Um jornal da região, chamado Gazeta do Sul, publicou a nota de falecimento, de forma indignada, culpabilizou Castilho pela morte desta senhora, indicando uma série de razões para não a ter prendido. Na redação do jornal citam vários abaixo-assinados feitos pelos governadores de Sena e da Província de Moçambique também questionando as razões de tal prisão. Assim, percebemos que existiu uma mobilização contrária ao desmantelamento da imagem de dona Luísa que vai buscar na memória das expedições de 1869 as prestezas feitas por ela, aqui não evocando a figura do marido, mas ressaltando a dela.

Numero 223 - Série de 1884 Secção Civil - Ilma. Exma snra. - Agora mesmo acabo de receber um officio do capitão mor dos rios de Senna, em que me participa estar a gente de Massingire revoltada e convencido de que V. Excia. me há de anular, sustentar a dignidade e os direitos da nossa nação, a exemplo dos meus antecessores, apelo para o seu RECONHECIDO PATRIOTISMO, pedindo a V. Excia. se digne a prender os criminosos, a fazer conservar o socego d'aquelle praso da coròa, J. R. Palma Velho. E dona Luiza fez o quanto pode, fornecendo contigente (GAZETA DO SUL. Quelimane, ano 1, n. 8, p. 2).

Segue à reportagem um abaixo assinado de outro governador informando que compartilharam desta assinatura, comerciantes, proprietário, agricultores, ou seja, grande parte da população contrária a prisão da dona do Goengue. Mais interessante foi perceber que a mesma memória partilhada por Ferreira na qual evidenciou Belchior, à época marido dela, como prestativo e zeloso para com a coroa, agora é mobilizado para retratá-la. 


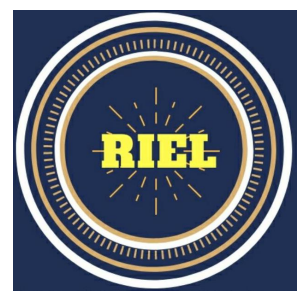

Uma petição foi incorporada na sequência destes abaixo assinados, mostrando que houve a reivindicação de $75 \%$ da população da vila de Quelimane exigindo a soltura dela. Atribuíam a Castilho de forma indireta o adjetivo de fazedor de vítimas.

Outra fonte importante e que também reflete um conceito sobre essa dona é a de Paul Guyot, francês que se dispunha a viajar pelo Zambeze nesta época como viajante e nesse caso a compõe como alguém de extremo poder. Publicada dois anos depois da obra de Castilho retratou a estadia de Guyot o Zambeze e suas observações do que viu e ouviu.

Mas quem é essa mulher? Fisicamente, ela é alta, bonita, bem formada, negra, com olhos brilhantes e brilhantes, mãos finas, pele gordinha e macia. Elegantemente vestida com uma tanga colorida, coberta com jóias de ouro trabalhadas no país, ela reina e domina sua terra. E apenas após se curvar que seus negros se aproximam dela; a um sinal, eles a reverenciam baixando a seus pés. Esta mulher compôs seu tribunal de um enxame de jovens, a quem ela cura, escolhe ou abusa de seu prazer. Não são eles escravos? (GUYOT, 1893, p. 87; Tradução nossa).

Evidencia-se que diferentes olhares foram lançados sobre a figura de Luísa, a qual teve tanta importância em seu contexto histórico que muitas pessoas se mobilizaram para defendê-la e atacála. Sua proeminência se confirma e sua influência fica registrada nas documentações deixadas pelos viajantes europeus e administradores portugueses que resolveram contar a seu respeito.

Por fim, percebemos nos relatos dos viajantes uma dicotomia hierárquica em relação à descrição do exercício de poder dos homens em comparação com o das mulheres, sobretudo, quando os discursos se direcionaram para as narrativas que traçaram representações das camadas sociais que detinham influência, poder político e econômico. Quando a mulher africana, mais especificamente, Luísa de Goengue exercia poder sua ação era descrita como despótica e excessiva, mas, a mesma descrição narrativa não foi realizada para os homens, brancos, que usassem de violência para com seus subalternos e inimigos. Para os homens negros, esse discurso emergia se as suas ações representassem rebeldia ou insubmissão para os portugueses. 


\section{REFERÊNCIAS}

ANDRADA, J. C. P. Relatório de uma viagem às terras dos landins. Lisboa: Imprensa Nacional, 1885. Disponível em http://www.archive.org. Acesso em 15 de outubro de 2016.

BAKHTIN, M. Os gêneros do discurso. In: . Estética da criação verbal. Trad. Paulo Bezerra. 4. ed. São Paulo: Martins Fontes, [1979] 2003.

BARROS, J. A. Fontes históricas: revisitando alguns aspectos primordiais para a Pesquisa Histórica. Mouseion, n. 12, mai/ago/2012, pp.129-159.

CAPELA, J. Donas, senhores e escravos. Porto: Edições Afrontamentos, 1995.

CASTILHO, A. Relatório da guerra da Zambézia em 1888. Lisboa: Imprensa Nacional, 1891. Disponível em http://www.archive.org. Acesso em 15 de janeiro de 2014.

COURRET, C. A l'est et à l'ouest dans l 'Océan Indien: Sumatra, la côte du Poivre, massacre de la mission Wallon à Atjeh, Zanzibar, Nossi Bé, Mozambique, 1884. Disponível em http:// gallica.bnf.fr/ark:/12148/bpt6k5475229m?rk=42918;4. Acesso em 25 de julho de 2017.

DIAS, M. O. L. S. Novas subjetividades na pesquisa histórica feminista: uma hermenêutica das diferenças. Estudos Feministas, ano 2, 1994, pp. 373-382.

FERREIRA, J. J. Recordações da expedição da Zambézia em 1869. Elvas: Typographia Progresso, 1891, 2a Edição. Disponível em http://www.archive.org. Acesso em 15 outubro 2015.

GAFFARD, R. Exploration au Zambèse: situation géographique et aspect du pays, flore, faune, habitants. Paris: Yve Éthiou-Pérou, 1882. Disponível em http://gallica.bnf.fr/ark:/12148/ bpt6k201051r. Acesso em 25 de julho de 2017.

GAZETA DO SUL. D. Luísa da Cruz, Quelimane, ano 1, n. 8, p. 2, 13 de julho de 1889. Folha semanal. Disponível em Biblioteca Nacional Digital: http://purl.pt/26330/4/344347 PDF/ 344347 PDF 24-C-R0150/344347 0000 1-4 t24-C-R0150.pdf. Acessado em 05 de maio de 2016.

GUYOT, P. Voyage au Zambèse. Paris: Joseph André et Cie, 1895. Disponível em: http:// www.archive.org. Acesso em 15 de outubro de 2016.

ISAACMAN, A. A tradição de resistência em Moçambique: o vale do Zambeze, 1850-1921. Porto: Afrontamento, 1979.

JUNQUEIRA, M. A. Elementos para uma discussão metodológica dos relatos de viagem como fonte para o historiador. Cadernos de Seminários de Pesquisa, vol. II. São Paulo: USP/FFLCH, 2011, pp. 44-61. 
LOBATO, A. Colonização senhorial da Zambézia e outros estudos. Lisboa: Junta de Investigações de Ultramar, 1962.

MAGALHÃES, J. P. Trajetórias e resistências de mulheres sob o colonialismo português (Sul de Moçambique, XX). Tese de Doutorado em História Social, Universidade de São Paulo, São Paulo, 2016.

MARGARIDO, A. Algumas formas de hegemonia africana nas relações com europeus. Actas da $1^{\mathrm{a}}$ Reunião Internacional de História da África, IICT, 1998, pp. 383-406.

MARTINS, J. P. O. O Brazil e as colônias portuguesas 1845-1894. Lisboa: Parceria A. M. Pereira, 1920.

NEWITT, M. D. D; GARLAKE, P. S. The 'aringa' at Massangano. The Journal of African History, v. 8; march, 1967, pp.133-156.

. História de Moçambique. Lisboa: Publicações Europa América, 1995.

OLIVEIRA, D. J. A província de Moçambique e o Bonga. Coimbra: Imprensa Académica, 1879. Disponível em: http://www.archive.org. Acesso em 12 de janeiro de 2014.

RODRIGUES, E. Chiponda, a "senhora que tudo pisa com os pés". Estratégias de poder das donas dos prazos do Zambeze no século XVIII. I Simpósio Internacional, UFBA, 2000.

SOIHET, R. História das mulheres e história de gênero: um depoimento. Cadernos Pagú (11) 1998, pp.77-87.

WISSENBACH, M. C. C. Teodora Dias da Cunha: construindo um lugar para si no mundo da escrita e da escravidão. In: XAVIER, G.; BARRETO, J. F.; GOMES, F. (Orgs.). Mulheres negras no Brasil escravista e no pós-emancipação. São Paulo: Selo Negro, 2012. 